\title{
An Evidence-Based Guide for Medical Students: How to Optimize the Use of Expanded-Retrieval Platforms
}

\author{
Cyrus A. Pumilia $^{1}$, Spencer Lessans ${ }^{1}$, David Harris ${ }^{2}$ \\ 1. Medicine, University of Central Florida College of Medicine, Orlando, USA 2. Medical Education, University of \\ Central Florida College of Medicine, Orlando, USA
}

Corresponding author: Spencer Lessans, spencer_lessans@knights.ucf.edu

\begin{abstract}
Recommendations have been made for improving medical education based on the available evidence regarding learning. Traditional learning methods in medical education (e.g. reading from textbooks) do not ensure long-term retention. However, expanded-retrieval studying methods have been shown to improve studying efficiency. Using evidence-based practices to optimize an expanded-retrieval platform has the potential to greatly benefit knowledge acquisition and retention for medical students. This literature review was conducted to identify the best practices of expanded-retrieval platforms.
\end{abstract}

Themes within learning that promote knowledge gain and retention include presentation of related categorical information, schema formation, dual-coding, concrete examples, elaboration, changes in text appearance, and interleaving. Presentation of related categorical material together may mitigate retrievalinduced forgetting (RIF). Spaced retrieval helps to reinforce schema formation by solidifying the framework the individual students form when learning the material. Dual-coding improves learning by creating more neural pathways. Multiple concrete examples can be compared by students to see their respective differences, highlighting the true underlying principle. Variation in text appearance is most useful during the initial, short-term inter-study intervals. Interleaving is a theme where different topics are combined in the same study session and is unpopular with students but shown to be successful. Students' subjective competency ratings of new material are largely inaccurate. More in-depth processing and learning methods that give off a sense of lower competency are actually associated with improved long-term retention.

Expanded-retrieval platforms should utilize these evidence-based components of learning to increase knowledge gain and retention within all fields of medical education.

Received 08/01/2020

Review began 08/17/2020 Review ended 09/06/2020 Published 09/11/2020

(c) Copyright 2020

Pumilia et al. This is an open access article distributed under the terms of the Creative Commons Attribution License CC-BY 4.0., which permits unrestricted use, distribution, and reproduction in any medium, provided the original author and source are credited.

Categories: Medical Education

Keywords: spaced repetition, retrieval, optimization, anki, medical education, retention, knowledge acquisition, evidence-based learning, expanded-retrieval, active learning

\section{Introduction And Background}

Memory can be trained to seemingly impossible levels [1], indicating that there may be potential for improvement of how knowledge is acquired in medical school. Accordingly, there have been recommendations for improving medical education based on the available evidence in cognitive science regarding learning [2, 3]. As technology continues to expand, more web-based materials are being used by medical students, many of which being expanded-retrieval platforms. Expanded-retrieval platforms are platforms commonly used for content review where the interval between testing of subject matter is gradually increased. These platforms allow students to study information in increasing inter-study intervals (increasing time between the testing or studying of subject matter) with retrieval-based practice. Expandedretrieval may also be called "spaced repetition," "expanding rehearsal," "graduated intervals," "repetition spacing," and “spaced retrieval.”

Previous studies have demonstrated that learning in medical education does not often ensure long-term retention [4-6]. An experiment performed in residents showed that implementation of a tutorial on clinical guidelines improved mean knowledge scores from $50 \%$ pre-test to immediate post-test scores of $76 \%$. However, scores then dropped to approximately half of what was gained between three and eight days and to an unmeasurable gain in retention at fifty-five days [4]. Even students that have been shown to benefit from this testing effect fall back to normal forgetting characteristics if not re-exposed to the material [7]. In the study conducted by Kerfoot in 2010, retention at one week was improved, but at six months, there was no increased retention [8].

Expanding retrieval has been shown to improve studying efficiency, netting similar test scores at the end of a study period as equal-spacing but with lower amounts of total repetitions [9]. Students given immunology and physiology material showed more improvements in testing after trials of expanding intervals rather 
than with equal intervals when the total number of repetitions are held constant [10]. It seems that, when the number of repetitions are held constant, spacing of repetitions is more effective than cramming them or spreading them equally. This has also been shown in urology residents using a web-based course [7].

Active retrieval is an effective learning tool in and of itself [8], typically producing greater returns than restudying [11]. Subjects learned paragraph readings better when some words were slightly blocked out, forcing subjects to continue reading via a process called "generative retrieval" [12]. Many expanded-retrieval platforms use a feature called "cloze deletions" based on the process of generative retrieval where users can create flashcards that hide words of a sentence. Generative retrieval was used for learning of cardiac anatomy in medical students and residents and was shown to be more effective over standard studying methods [13].

Multiple studies have recommended the use of expanded-retrieval platforms for medical students [14, 15]. The recommendations are made in accordance with how these platforms are used, but much of the current research points to future technology. The question remains as to how expanded-retrieval platforms can currently be implemented in medical education.

\section{Review}

\section{Methods}

A PubMed search was conducted of appropriate terms, including all relevant iterations of expandedretrieval: "Spaced AND repetition", "Expanding AND rehearsal”, "Graduated AND intervals", "Repetition AND spacing”, "Repetition AND scheduling”, "Spaced AND retrieval”, "Expanded AND retrieval”, "retrieval AND practice AND learn”, "retrieval AND practice”, “medical AND student AND recall”, "interleaving AND learning”, "flashcard AND learn”, “dual AND coding”, “dual AND coding AND learn”, and "Retrieval AND induced AND forgetting AND education.” The literature search was conducted in June 2018.

Articles were included based on relevancy to the population in question and the application in question. For articles to be included, they had to meet the following criteria: they must have been published in English and they had to study or analyze spaced repetition methods in the process of learning for the purposes of education. Studies that looked at spaced repetition methods outside the field of education were not included. For example, studies concerning the use of expanded-retrieval for the purposes of brain injury rehabilitation were excluded, and studies concerning the use of interleaving for the purposes of motor skill acquisition were similarly excluded.

In total, 21 papers were found to be relevant and read in full by the authors. There was no blinding done when analyzing whether the papers were to be included or not. The papers were included if they met the inclusion criteria above and fell under one of the themes of expanded-retrieval platforms (Figure 1). This narrative review was not designed to be a systematic analysis of the use of expanded-retrieval platforms within medical education. Rather, it analyzes and summarizes the current literature to determine what themes of expanded-retrieval platforms are evidence-based.

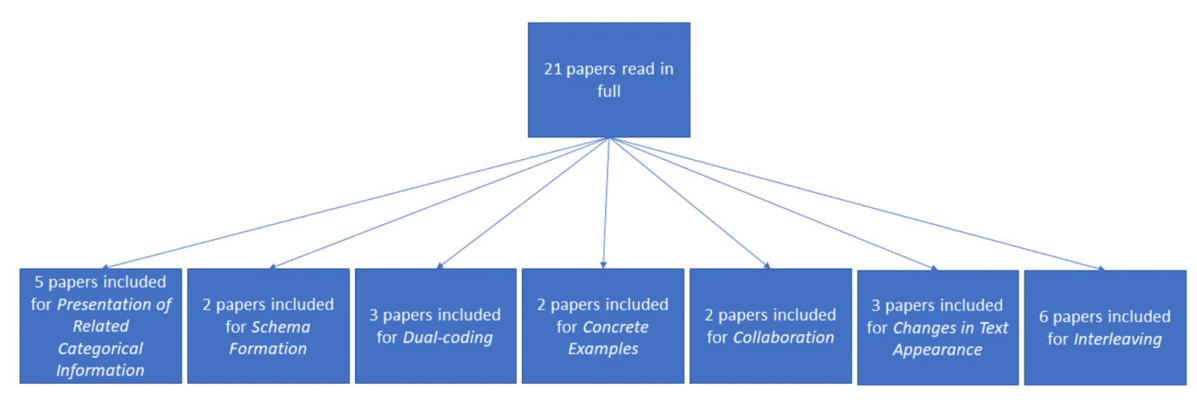

FIGURE 1: Article Inclusion Process

\section{Results and analysis}

Themes that can be implemented within expanded-retrieval platforms include presentation of related categorical information, schema formation, dual-coding, concrete examples, elaboration, changes in text appearance, and interleaving. The role of each of these themes in learning and expanded-retrieval programs will be discussed below.

Presentation of Related Categorical Information

Presentation of related categorical material together may mitigate retrieval-induced forgetting (RIF) [16, 17]. 


\section{Cureus}

When a category of information is learned, and only a portion of said category is presented for retrieval at a later date, the memory of the presented information is strengthened while the memory of unpresented information is weakened, even if retrieval is unsuccessful [18]. The most significant effects of RIF are seen when closely related facts are tested (Figure 2) [17]. However, information forgotten through RIF was learned more quickly than other not-yet-seen information that was presented, thereby reversing the effects of RIF [19]. Subjects with more anxiety have been shown to have some protection against RIF [20], which may have implications for RIF in proximity to important examinations that increase anxiety. Expanded-retrieval platforms can minimize RIF by allowing for viewing of material that is not explicitly tested but is present upon presentation of related material, such as supporting information on flashcards. In doing so, medical students will be presented with a greater amount of information than through conventional studying methods.
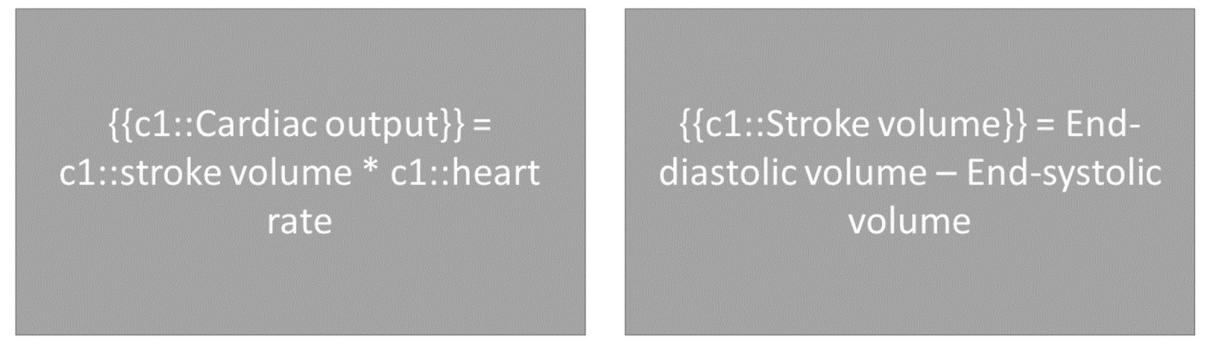

FIGURE 2: Presentation of related information: testing recognition of different concepts within the same field

$\{\{c 1::\}\}$ is used in spaced repetition programs to add 'Cloze deletions' where the phrase contained in the brackets is hidden for the user to recall.

Schema Formation

Schema formation, a student's "framework" in which they fill knowledge, has been shown to be important for long-term retention. Schema reinforcement seems to be important for reinforcement in learning [21]. Spaced retrieval helps to reinforce schema formation by solidifying the framework the individual students form when learning the material (Figure 3) [22]. As a result, it may be important to implement the different framework types that work best for the different individual learners into the expanded-retrieval program.

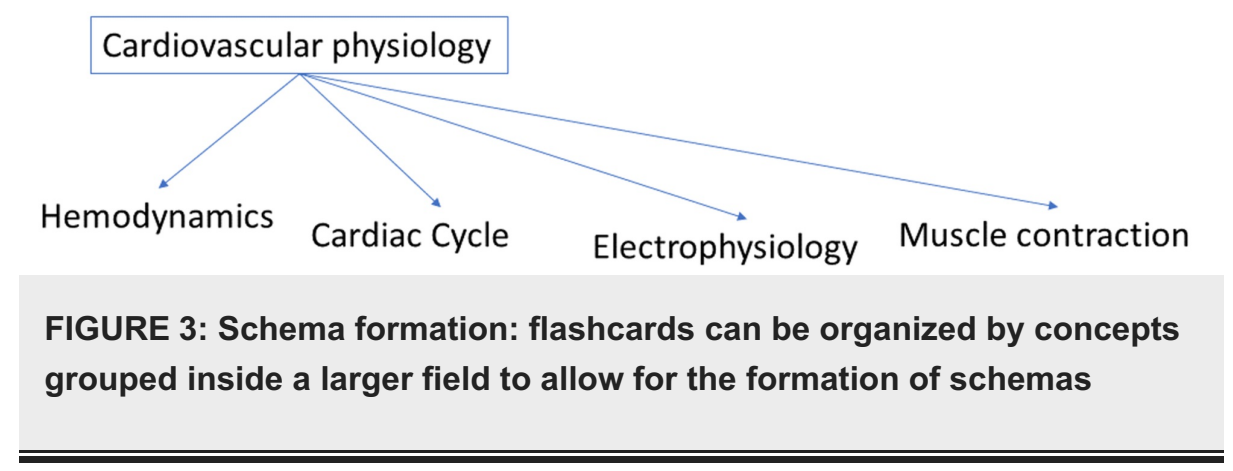

Dual-Coding

Dual-coding, the use of multiple sensory inputs to learn a specific set of information, also can improve retention. It has been shown to be effective in healthcare fields [23] though its main effects have been shown for vocabulary and foreign language learning [24]. It is thought to improve learning by creating more neural pathways, thereby increasing the chance of pathway utilization during an attempted recall. Multisensory learning seems to facilitate learning via one sensory modality as well and may be used as a gauge of proper schema formation [21]. Expanded-retrieval programs can make use of this by combining both verbal and visual information electronically when presenting material (Figure 4). 


\section{Cureus}

$\{\{c 1:$ Wolff-Parkinson White

Syndrome $\}$ is an example of an

arrhythmia involving an

accessory pathway
The EKG below suggests

$\{\{c 1:$ Wolff-Parkinson-White

Syndrome $\}\}$

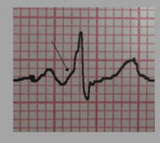

\section{FIGURE 4: Dual-coding: both text and images can be used to enhance learning of a topic}

$\{\{c 1::\}\}$ is used in spaced repetition programs to add 'Cloze deletions' where the phrase contained in the brackets is hidden for the user to recall.

Concrete Examples

Concrete examples also help students understand complex concepts and recognize patterns. Giving concrete examples for concepts can help students connect concepts (Figure 5) [25], but may pose a risk for the disregarding of concepts in exchange for simply following the specific example [26]. Accordingly, students should utilize multiple examples that go along with their expanded-retrieval platform's concept-based presentations. Multiple examples can be compared to see their respective differences, highlighting the true underlying principle. More examples may help to ensure that an accurate pattern is seen and the simple memorization of one example does not occur.
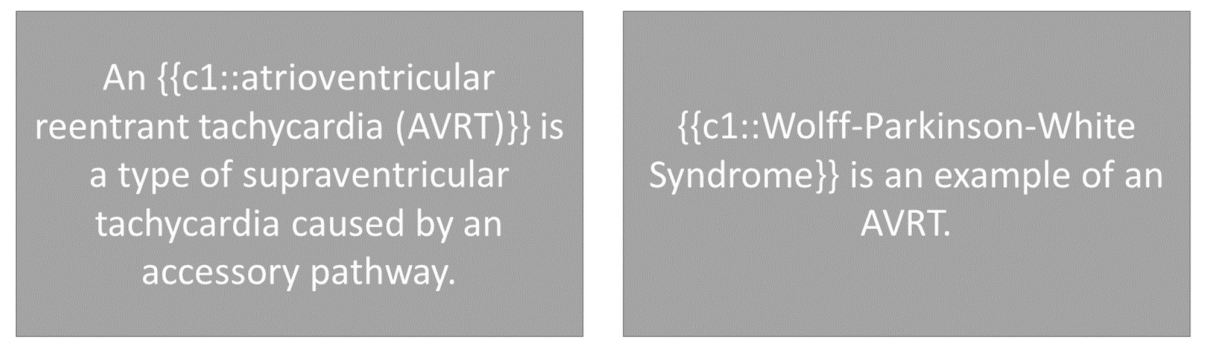

\section{FIGURE 5: Concrete examples: specific examples of concepts elaborated in the previous flashcards can be given}

$\{\{c 1::\}\}$ is used in spaced repetition programs to add 'Cloze deletions' where the phrase contained in the brackets is hidden for the user to recall.

Elaboration

Elaboration, an act of allowing the mind to freely question a topic, has been shown to be effective for learning. Central to elaboration is the process of overcoming uncertainty, a process that is crucial for learning [27]. Accordingly, students may utilize elaboration when expanded-retrieval fails, and they are forced to re-study a topic. Elaboration simply consists of a student letting the mind wander about the topic, self-testing, and finding answers to the questions that come to mind (Figure 6). This may require temporary exit of the expanded-retrieval platform, a potential drawback to utilizing these platforms. An important note to make is that elaboration must be made with review of information known to be accurate, as elaboration techniques may lead students astray to false understandings of material [28].

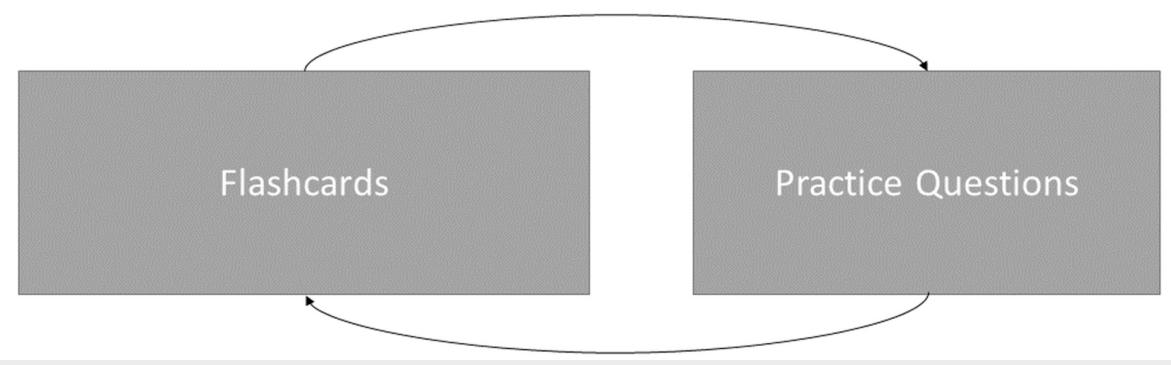




\section{Cureus}

FIGURE 6: Elaboration: flashcards can be utilized with other resources to consolidate learning

Changes in Text Appearance

Changes in text appearance, including inversion of words [29] and hard to read fonts [30], result in improved retention (Figure 7). The effects are thought to be due to activation of deeper processing of the material. While this effect is attainable outside an expanded-retrieval platform, this variation impact on learning can certainly translate to within these platforms. For example, a student can change the size of the computer window used, altering the shape of the text appearance. A student may also change the colors of the program if that platform allows so.
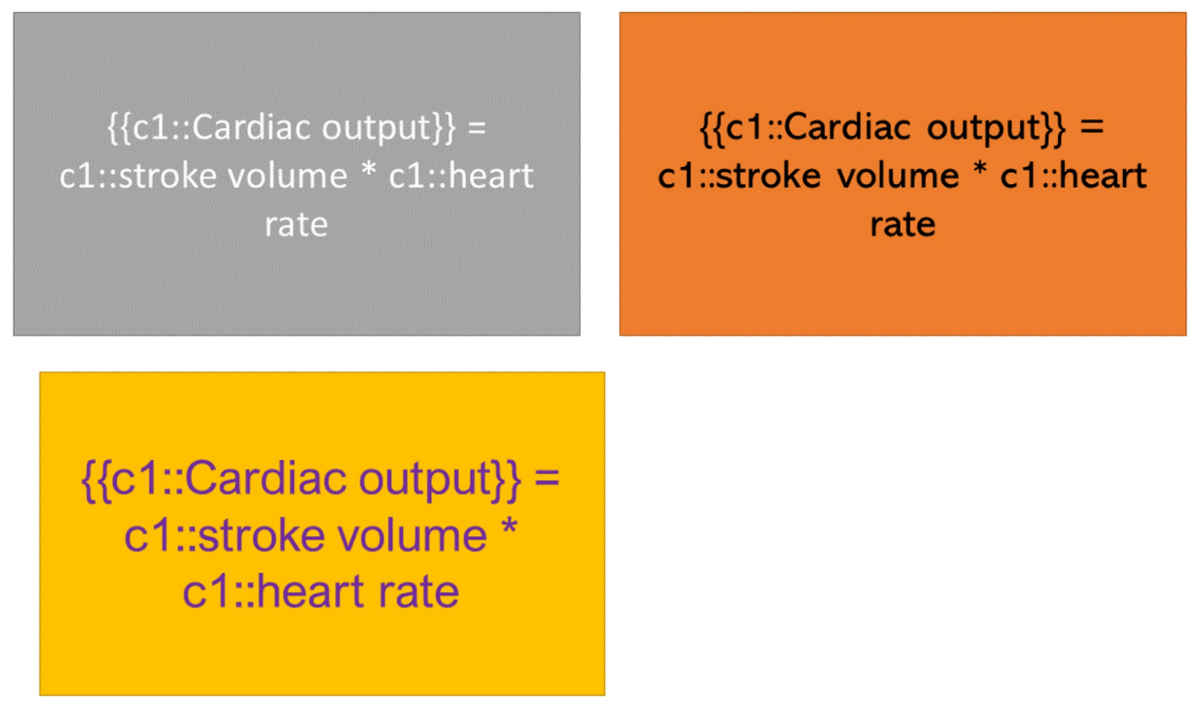

\section{FIGURE 7: Changes in text appearance: changing the appearance will prevent rote memorization}

$\{\{c 1::\}\}$ is used in spaced repetition programs to add 'Cloze deletions' where the phrase contained in the brackets is hidden for the user to recall.

Variation seems to be most useful during the initial, short-term inter-study intervals, whereas at longer inter-study intervals, it may actually inhibit further retention [31], thought to be due to the interference with the initial framework, or schema, that the memory was stored in. This inhibitory effect was greatest for recall testing rather than for recognition testing. Accordingly, while variation in appearance may initially help in the learning process, students should be weary of too much variation at long inter-study intervals.

Interleaving

Interleaving is the act of mixing topics during a study session (Figure 8). Though students report beliefs that interleaving would be counterproductive [32], a large body of research supports its use. Interleaving has been shown to be effective for both visual stimuli [33] and for textual learning [34]. It must be noted that interleaving has been shown to be ineffective for studying subjects that are too far apart, such as anatomy and Indonesian language [35]. Interleaving improves learning by allowing discriminative-contrast, as learning of different concepts in the same study session allows for the direct comparison between the two, which can improve future performance [36]. In interleaving, difficulty seems higher. It appears that the more difficulty the learner perceives, the stronger the long-term retention effects [37]. In support of this contrast, subjects rated massing (combining similar topics when studying) as more productive than interleaving, though interleaving was objectively more productive [33-34]. 

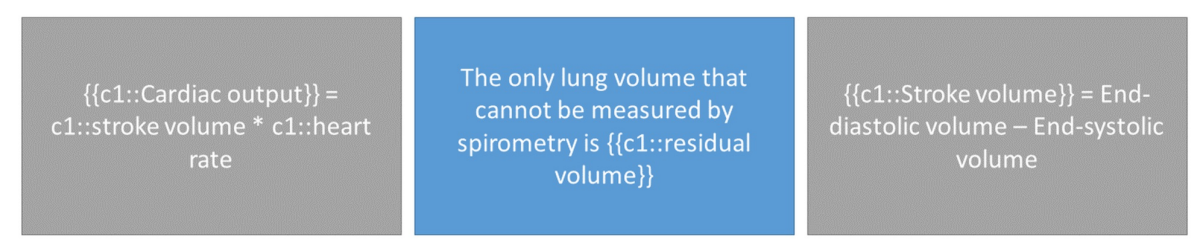

\section{FIGURE 8: Interleaving: mixing in unrelated topics can help aid comprehension}

$\{\{c 1::\}\}$ is used in spaced repetition programs to add 'Cloze deletions' where the phrase contained in the brackets is hidden for the user to recall.

It is also important to reduce reliance on students' subjective competency ratings as short-term perceptions have been shown to be largely inaccurate [38]. More in-depth processing and learning methods that give off a sense of lower competency are associated with improved long-term retention [38]. Retrieval is a way to alleviate the false sense of knowledge gained while studying that has been shown to be inaccurate [39]. Effective interventions for improving subjective measures can be done by spaced retrieval platforms by consistently presenting the material again and again, the interval being modified with the personal knowledge of failed retrieval or for desired increased frequency at times where greater repetition is desired (i.e. if an examination is soon).

There is data that suggests that expanding-retrieval, recall, and/or spacing is not the best choice for certain purposes. For example, the positive effects of expanding-retrieval are likely not seen from a single study session [40]. Also, a study in residents with a web-based, equally-spaced interval program showed no improvement in subsequent test performance unless the subjects were first-year interns [41], which shows that expanding-retrieval platforms may not be relevant to all medical education populations. Furthermore, testing with feedback was shown to be superior to simple, spaced study in residents on medical knowledge [42].

We also know that testing enhances learning [43] and improves access to marginal knowledge even without feedback [40, 44]. Testing, given that the answer choices are close and plausible (i.e. "competitive"), but clearly have a correct or incorrect component (so that the incorrect answers can be seen and identified), can foster recall/further learning of both correct and incorrect answer choices [45]. Some studies have shown lack of benefit of multiple choice over retrieval [44], which seems to be due to the answer choices not facilitating proper comparison of information. Testing may even have a generalizable effect to material not tested upon. A generalized testing effect was seen in language learning where testing improves retention of other, recently-studied language terms that were not tested [46]. Unfortunately, testing takes more time than expanded-retrieval and integrating testing with spacing is more difficult than simple expanding-retrieval platforms. Nonetheless, this sheds light on the scope of efficacy and the need for other learning tools to be integrated into a student's learning appropriately.

\section{Conclusions}

The current evidence provides guidance for students to optimize their use of expanded-retrieval platforms. These platforms can utilize evidence-based components of learning such as presentation of related categorical material together, schema formation, and interleaving, among the others mentioned to increase knowledge gain and retention. All of these themes have been shown to improve knowledge acquisition. Expanded-retrieval platforms, such as Anki, are already commonly used by medical students. The integration of peer-reviewed research into expanded-retrieval platform algorithm optimization may be a direction for future research.

\section{Additional Information}

\section{Disclosures}

Conflicts of interest: In compliance with the ICMJE uniform disclosure form, all authors declare the following: Payment/services info: All authors have declared that no financial support was received from any organization for the submitted work. Financial relationships: All authors have declared that they have no financial relationships at present or within the previous three years with any organizations that might have an interest in the submitted work. Other relationships: All authors have declared that there are no other relationships or activities that could appear to have influenced the submitted work.

\section{References}

1. Bartol TM, Bromer C, Kinney J, Chirillo MA, Bourne JN, Harris KM, Sejnowski TJ: Nanoconnectomic upper bound on the variability of synaptic plasticity. Elife. 2015, 4:10778. 10.7554/eLife.10778 
2. Patel VL, Yoskowitz NA, Arocha JF: Towards effective evaluation and reform in medical education: a cognitive and learning sciences perspective. Adv Health Sci Educ Theory Pract. 2009, 14:791-812. 10.1007/s10459-007-9091-1

3. Weidman J, Baker K: The cognitive science of learning: concepts and strategies for the educator and learner . Anesth Analg. 2015, 121:1586-1599. 10.1213/ane.0000000000000890

4. Bell DS, Harless CE, Higa JK, Bjork EL, Bjork RA, Bazargan M, Mangione CM: Knowledge retention after an online tutorial: a randomized educational experiment among resident physicians. J Gen Intern Med. 2008, 23:1164-1171. 10.1007/s11606-008-0604-2

5. Greb AE, Brennan S, McParlane L, Page R, Bridge PD: Retention of medical genetics knowledge and skills by medical students. Genet Med. 2009, 11:365-370. 10.1097/GIM.0b013e31819c6b2d

6. Schmidmaier R, Ebersbach R, Schiller M, Hege I, Holzer M, Fischer MR: Using electronic flashcards to promote learning in medical students: retesting versus restudying. Med Educ. 2011, 45:1101-1110. 10.1111/j.1365-2923.2011.04043.x

7. Pastotter B, Bauml KH: Retrieval practice enhances new learning: the forward effect of testing . Front Psychol. 2014, 5:286. 10.3389/fpsyg.2014.00286

8. Kerfoot BP: Adaptive spaced education improves learning efficiency: a randomized controlled trial . J Urol. 2010, 183:678-681. 10.1016/j.juro.2009.10.005

9. Dobson JL: Effect of uniform versus expanding retrieval practice on the recall of physiology information . Adv Physiol Educ. 2012, 36:6-12. 10.1152/advan.00090.2011

10. Kerfoot BP, Fu Y, Baker H, Connelly D, Ritchey ML, Genega EM: Online spaced education generates transfer and improves long-term retention of diagnostic skills: a randomized controlled trial. J Am Coll Surg. 2010, 211:331-337. 10.1016/j.jamcollsurg.2010.04.023

11. Roediger HL, Butler AC: The critical role of retrieval practice in long-term retention. Trends Cogn Sci. 2011, 15:20-27. 10.1016/j.tics.2010.09.003

12. DeWinstanley PA, Bjork EL: Processing strategies and the generation effect: implications for making a better reader. Mem Cognit. 2004, 32:945-955. 10.3758/bf03196872

13. Kleiman AM, Forkin KT, Bechtel AJ, Collins SR, Ma JZ, Nemergut EC, Huffmyer JL: Generative retrieval improves learning and retention of cardiac anatomy using transesophageal echocardiography. Anesth Analg. 2017, 124:1440-1444. 10.1213/ane.0000000000002004

14. Yeh DD, Park YS: Improving learning efficiency of factual knowledge in medical education . J Surg Educ. 2015, 72:882-889. 10.1016/j.jsurg.2015.03.012

15. Augustin M: How to learn effectively in medical school: test yourself, learn actively, and repeat in intervals . Yale J Biol Med. 2014, 87:207-212.

16. Buchli DR, Storm BC, Bjork RA: Explaining retrieval-induced forgetting: a change in mental context between the study and restudy practice phases is not sufficient to cause forgetting. Q J Exp Psychol. 2016, 69:1197-1209. 10.1080/17470218.2015.1076866

17. Anderson MC, Bjork RA, Bjork EL: Remembering can cause forgetting: Retrieval dynamics in long-term memory. J Exp Psychol [Learn Mem Cogn]. 1994, 20:1063-1087. 10.1037//0278-7393.20.5.1063

18. Storm BC, Bjork EL, Bjork RA, Nestojko JF: Is retrieval success a necessary condition for retrieval-induced forgetting?. Psychon Bull Rev. 2006, 13:1023-1027. 10.3758/BF03213919

19. Storm BC, Bjork EL, Bjork RA: Accelerated relearning after retrieval-induced forgetting: the benefit of being forgotten. J Exp Psychol [Learn Mem Cogn]. 2008, 34:230-236. 10.1037/0278-7393.34.1.230

20. Koessler S, Steidle L, Engler H, Kissler J: Stress eliminates retrieval-induced forgetting---does the oral application of cortisol?. Psychoneuroendocrinology. 2013, 38:94-106. 10.1016/j.psyneuen.2012.05.004

21. Ruiter DJ, van Kesteren MT, Fernandez G: How to achieve synergy between medical education and cognitive neuroscience? an exercise on prior knowledge in understanding. Adv Health Sci Educ Theory Pract. 2012, 17:225-240. 10.1007/s10459-010-9244-5

22. Larsen DP: Planning education for long-term retention: the cognitive science and implementation of retrieval practice. Semin Neurol. 2018, 38:449-456. 10.1055/s-0038-1666983

23. Hartland W, Biddle C, Fallacaro M: Audiovisual facilitation of clinical knowledge: a paradigm for dispersed student education based on Paivio's Dual Coding Theory. AANA J. 2008, 76:194-198.

24. Danan M: Reversed subtitling and dual coding theory: new directions for foreign language instruction . Lang Learn. 1992, 42:497-527. 10.1111/j.1467-1770.1992.tb01042.x

25. Weinstein Y, Madan CR, Sumeracki MA: Teaching the science of learning . Cogn Res Princ Implic. 2018, 3:2. 10.1186/s41235-017-0087-y

26. LeFerve JA, Dixon P: Do written instructions need examples? . Cogn Instr. 1986, 3:1-30. 10.1207/s1532690xci0301_1

27. Overoye AL, Storm BC: Harnessing the power of uncertainty to enhance learning . Transl Issues Psychol Sci. 2015, 1:140-148. 10.1037/tps0000022

28. Clinton V, Alibali MW, Nathan MJ: Learning about posterior probability: do diagrams and elaborative interrogation help?. J Exp Educ. 2016, 84:579-599. 10.1080/00220973.2015.1048847

29. Sungkhasettee VW, Friedman MC, Castel AD: Memory and metamemory for inverted words: illusions of competency and desirable difficulties. Psychon Bull Rev. 2011, 18:973-978. 10.3758/s13423-011-0114-9

30. Alter AL, Oppenheimer DM, Epley N, Eyre RN: Overcoming intuition: metacognitive difficulty activates analytic reasoning. J Exp Psychol Gen. 2007, 136:569-576. 10.1037/0096-3445.136.4.569

31. Bjork RA, Appleton-Knapp SL, Wickens TD: Examining the spacing effect in advertising: encoding variability, retrieval processes, and their interaction. J Consum Res. 2005, 32:266-276. 10.1086/432236

32. Wissman KT, Rawson KA, Pyc MA: How and when do students use flashcards? . Memory. 2012, 20:568-579. 10.1080/09658211.2012.687052

33. Kornell N, Bjork RA: Learning concepts and categories: is spacing the "enemy of induction"? . Psychol Sci. 2008, 19:585-592. 10.1111/j.1467-9280.2008.02127.x

34. Zulkiply N, McLean J, Burt JS, Bath D: Spacing and induction: application to exemplars presented as auditory and visual text. Learn Instr. 2012, 22:215-221. 10.1016/j.learninstruc.2011.11.002

35. Hausman H, Kornell N: Mixing topics while studying does not enhance learning . J Appl Res Mem. 2014, 


\section{Cureus}

3:153-160. 10.1016/j.jarmac.2014.03.003

36. Birnbaum MS, Kornell N, Bjork EL, Bjork RA: Why interleaving enhances inductive learning: the roles of discrimination and retrieval. Mem Cognit. 2013, 41:392-402. 10.3758/s13421-012-0272-7

37. Bjork R: Memory and meta-memory considerations in the training of human beings. Metacognition: Knowing About Knowing. Metcalfe J, Shimamura A (ed): MIT Press, Cambridge, MA; 1994. 185:205.

38. Bjork RA, Dunlosky J, Kornell N: Self-regulated learning: beliefs, techniques, and illusions. Annu Rev Psychol. 2013, 64:417-444. 10.1146/annurev-psych-113011-143823

39. Koriat A, Bjork RA: Illusions of competence during study can be remedied by manipulations that enhance learners' sensitivity to retrieval conditions at test. Mem Cognit. 2006, 34:959-972. 10.3758/BF03193244

40. Karpicke JD, Roediger HL: Is expanding retrieval a superior method for learning text materials? . Mem Cognit. 2010, 38:116-124. 10.3758/mc.38.1.116

41. Matos J, Petri CR, Mukamal KJ, Vanka A: Spaced education in medical residents: an electronic intervention to improve competency and retention of medical knowledge. PLoS One. 2017, 12:0181418. 10.1371/journal.pone.0181418

42. Larsen DP, Butler AC, Roediger HL: Repeated testing improves long-term retention relative to repeated study: a randomised controlled trial. Med Educ. 2009, 43:1174-1181. 10.1111/j.1365-2923.2009.03518.x

43. Binks S: Testing enhances learning: a review of the literature . J Prof Nurs. 2018, 34:205-210. 10.1016/j.profnurs.2017.08.008

44. Cantor AD, Eslick AN, Marsh EJ, Bjork RA, Bjork EL: Multiple-choice tests stabilize access to marginal knowledge. Mem Cognit. 2015, 43:193-205. 10.3758/s13421-014-0462-6

45. Little JL, Bjork EL, Bjork RA, Angello G: Multiple-choice tests exonerated, at least of some charges: fostering test-induced learning and avoiding test-induced forgetting. Psychol Sci. 2012, 23:1337-1344. 10.1177/0956797612443370

46. Cho KW, Neely JH, Crocco S, Vitrano D: Testing enhances both encoding and retrieval for both tested and untested items. Q J Exp Psychol. 2006, 70:1211-1235. 10.1080/17470218.2016.1175485 